\title{
LA INTERVENCIÓN CONCURRENTE DEL CÓNYUGE COMO REQUISITO DE EFICACIA DEL ACTO JURÍDICO SEGÚN EL ARTÍCULO 315 DEL CÓDIGO CIVIL PERUANO
}

\author{
Fernando Arias - Stella Castillo*
}

\section{RESUMEN}

Breve reflexión sobre las diversas interpretaciones que se vienen efectuando del artículo 315 del Código Civil Peruano, dado que la posición de la jurisprudencia relativa a considerar al referido artículo como un supuesto de nulidad del acto jurídico por falta de manifestación de voluntad del agente, viene siendo cuestionada doctrinariamente. El texto, nos aproxima a la noción que la falta del concurso del cónyuge en los actos de disposición de los bienes gananciales, no es una vulneración del núcleo duro del Acto Jurídico por falta de manifestación de voluntad, sino que se trataría en rigor de un supuesto de ineficacia.

Palabras clave: Acto jurídico, nulidad, bienes de gananciales, bienes sociales

\author{
THE CONCURRENT INTERVENTION OF THE SPOUSE AS A \\ REQUIREMENT FOR THE EFFECTIVENESS OF THE LEGAL ACT \\ ACCORDING TO ARTICLE 315 OF THE PERUVIAN CIVIL CODE
}

\section{ABSTRACT}

Brief reflection on the various interpretations that are being made on article 315 of the Peruvian Civil Code, because the position of the relative jurisprudence, related to considering the referred article as grounds for nullity of the legal act due to the lack of manifestation of will of the agent, is being questioned in terms of doctrine. The text approaches us to the notion that the lack of participation of the spouse in acts of disposition of the joint property is not an infringement of the hard core of the Legal Act because of a lack of manifestation of will; instead of this, properly speaking it would grounds for inefficiency.

Key words: Legal act, nullity, social goods

\footnotetext{
* Abogado, Docente de la Facultad de Derecho de la Universidad Femenina del Sagrado Corazón.

Recepción: 05-07-2012

Aceptación: 20-07-2012
} 


\section{INTRODUCCIÓN}

En primer lugar, quiero agradecer al Instituto de Familia, la nueva deferencia concedida en la publicación de estas breves reflexiones en torno al artículo 315 del Código Civil Peruano (anteriormente, lo hicieron con el artículo "El Matrimonio Putativo", en el Boletín $N^{\circ} 11$ del Instituto de la Familia).

Comenzaré señalando que el tema se acomete, en sentido figurado, un poco a "marcha forzada", pues es un tópico que casi no buscamos, sino que nos encontró. De hecho, con ocasión a la participación como jurado en un examen de grado para obtener el título de Bachiller de la Universidad Femenina del Sagrado Corazón-UNIFÉ, junto con el Dr. Guillermo Almenara (Magistrado de la Corte Suprema) y el Dr. Alipio Montes de Oca (Catedrático), hubo un expediente de nulidad de acto jurídico que me cautivó al punto de intentar una explicación sistemática e integral de la aplicación del artículo 315 del Código Civil Peruano.

En principio, es necesario señalar que el régimen de la sociedad de gananciales, que es el marco de referencia inmediato del artículo 315 del Código Civil, tiene una arista constitucional. $X$, ha sido el recordado César Barros Conti, eminente ex - Presidente de la Corte Suprema de la República, quien en su libro "Jurisprudencia Ejecutoriada", lo describe al narrar el Expediente $N^{\circ}$ 1860-81 Ayacucho, al señalar que el artículo 9 de la Constitución reza: "...UNA SOCIEDAD DE BIENES QUE SE SUJETA AL REGIMEN DE LA SOCIEDAD DE GANACIALES" (similar redacción se mantiene en el artículo 5 de la Constitución actual y en el artículo 3 del Proyecto de Ley de Reforma Constitucional de la Ley 27600) (Conti,2000)

La referencia es relevante, si tenemos en cuenta que muchos tratadistas nacionales, siguiendo la tradición clásica francesa de subordinar la eficacia de la voluntad a las reglas "que interesan al orden público y a las buenas costumbres" (artículo $6^{\circ}$ del CODE), como Benjamín Aguilar Llanos en "Régimen Patrimonial del Matrimonio", José Almeida Briceño en "La Desprotección del Cónyuge y el Tercero en la Sociedad de Gananciales" o la Dra. Mariana Mendoza Fiscalini en sus Apuntes de Clase sobre Análisis Económico del Derecho en el Matrimonio, adhieren la idea que una contravención del artículo 315 del Código Civil Peruano supone una nulidad absoluta por ir contra norma imperativa y/o de orden público. 
En una posición próxima, aunque matizada, tenemos al tratadista Juan Zarate del Pino, quien advierte en su artículo "El Régimen de Bienes Matrimoniales en el Código Civil Peruano", aparecido en el Libro "Análisis del Código Civil a 25 años de su Vigencia" (de la Universidad Inca Gracilazo de la Vega) que: "Cabe distinguir los actos relacionados con las necesidades ordinarias del hogar de aquellos otros que exceden de esas necesidades ordinarias. Para las primeras se consagra prácticamente el ejercicio indistinto, pues el ejercicio conjunto sería inoperativo, por lo que para esta clase de actos se considera que la sociedad es representada por cualquiera de ellos, presumiéndose que actúan con el consentimiento tácito del otro, mas, para actos de mayor trascendencia que exceden de los de simple administración como los de disposición o gravamen se requiere la intervención conjunta de ambos como requisito de validez del acto, por falta de manifestación de voluntad del agente".

Vale la pena recordar, hasta aquí, que existe el Pleno Jurisdiccional de la Corte Suprema de Justicia del Perú, del 18 de noviembre de 1997 que estableció, como criterio jurisprudencial que el acto jurídico por el que uno de los cónyuzes dispone, sea a título de gratuito u oneroso, de los bienes sociales sin la intervención de su consorte, es nulo por la causal de falta de manifestaciun de voluntad del agente.

En una posición diferente, podemos citar al tratadista en Derecho de Familia Alex Plácido Vilcachagua, quien adhiere la idea de la anulabilidad por contravención del interés protegido del cónyuge no interviniente de conformidad al artículo 315 del Código Civil.

Asimismo, el Dr. Rómulo Morales Hervias, en sus trabajos denominados "Estudios sobre Teoría General del Contrato" y "Nulidad e Inoponibilidad del Contrato versus Principio de la Buena Fe Pública Registral", asume la posición de que la contravención al artículo 315 del Código Civil no supone que haya invalidez (ni nulidad ni anulabilidad), sino un problema de ineficacia, que es la ausencia de legitimación.

A mayor abundamiento, el propio Dr. Héctor Cornejo Chávez, en "Régimen Matrimonial Peruano" (Revista de Derecho No 39 de la PUC) y en su clásico "Derecho Familiar Peruano" refiere que el matrimonio, siendo una compleja relación personal y patrimonial (Régimen de Bienes y Deudas) goza: de una vocación de permanencia que, concede facultades a los cónyuges sobre los bienes comunes que no deben ejercerse de modo que suponga 
extralimitación o abuso, franqueando la oposición al acto por parte del cónyuge no interviniente. Empero, respecto a los terceros, que si contrataron con el otro cónyuge advierte: "Parece que dichos terceros deben ser respetados, salvo que hubieran procedido de mala fe, esto es, sabiendo que el acto que celebraba el marido excedía de los limites de una administración regular".

A su turno, aunque referido a la legislación civil argentina, Bossert y Zannoni, en su obra "Manual de Derecho de Familia", reseñan: "El acto al que le falta el concurso de la voluntad del otro esposo exigido por los... está viciado de nulidad relativa, que puede ser demandada por el otro cónyuge. No está comprometido un interés público, sino el interés patrimonial de aquél..." (Bosser G. y E. Zannoni, 1989)

Creemos relevante apuntar que, en un importante trabajo sobre la teoría del acto jurídico, tal como el trabajo del recordado Maestro Lizardo Taboada Córdova ("Causales de Nulidad del Acto Jurídico", Revista Thémis $N^{\circ} 11$, Segunda Época), cuando se desarrolla la causal de la falta de manifestación de voluntad del agente, se precisa: Los supuestos que encajan dentro de esta primera causal de nulidad son los siguientes: - Incapacidad Natural, - Error en la Declaración, - Declaración hecha en Broma y Violencia. Lo que refuerza la noción, en una suerte de contrario, que el artículo 315 del Código Civil peruano no supone realmente un caso que encuadre al tipo de nulidad por falta de manifestación de voluntad del agente, sino otra cosa, mucho más próxima al caso del artículo 161 del Código Civil en donde se precisa la ineficacia del acto jurídico por el exceso en el límite de las facultades conferidas.

\section{CONCLUSIÓN}

La posición de la jurisprudencia relativa a considerar al referido artículo como un supuesto de nulidad del acto jurídico por falta de manifestación de voluntad del agente, viene siendo cuestionada doctrinariamente. 


\section{REFERENCIAS}

Barros Conti, César (2000) "Jurisprudencia Ejecutoriada" .. Compendio de "El Abogado y el Fiscal", "Jurisprudencia Civil y Procesal Civil", "Jurisprudencia Penal y Procesal Penal", "Los Avatares y sinsabores de la Justicia Peruana" y "Las deformas del Poder Judicial". Lima: Editorial Minerva.

Universidad Inca Garcilaso de la Vega (2010) "Anúlisis del Código Civila 25 años de su Vigencia" - Derecho de Familia - Alex Plácido Vilcachagua, Manuel Miranda Canales, Aída Kemelmajer de Carlucci y Juan Zárate del Pino. Lima: Editor Motivensa SRL.

Cornejo Chávez, Héctor. (1982) Derecho Familiar Peruano, - Sociedad Conyugal. Lima:Libreria Studium Editores.

Bossert, Gustavo y Eduardo Zannoni (1989) Manual de Derecho de Familia. $2^{\circ}$ Edición. Buenos Aires: Editorial Astrea. 
